\title{
THE
}

2018

\section{WearLight: Towards a Wearable, Configurable Functional NIR Spectroscopy System for Noninvasive Neuroimaging}

\author{
Manob Jyoti Saikia \\ University of Rhode Island \\ Walter G. Besio \\ University of Rhode Island \\ Kunal Mankodiya \\ University of Rhode Island, kunalm@uri.edu
}

Follow this and additional works at: https://digitalcommons.uri.edu/ele_facpubs

The University of Rhode Island Faculty have made this article openly available.

Please let us know how Open Access to this research benefits you.

This is a pre-publication author manuscript of the final, published article.

Terms of Use

This article is made available under the terms and conditions applicable towards Open Access

Policy Articles, as set forth in our Terms of Use.

\section{Citation/Publisher Attribution}

Saikia, M.J., Besio, W., \& Mankodiya, K. (2019). WearLight: Towards a Wearable, Configurable Functional NIR Spectroscopy System for Noninvasive Neuroimaging. IEEE Transactions on Biomedical Circuits and Systems, 13(1), 91-102. doi: 10.1109/TBCAS.2018.2876089

Available at: http://dx.doi.org/10.1109/TBCAS.2018.2876089

This Article is brought to you for free and open access by the Department of Electrical, Computer, and Biomedical Engineering at DigitalCommons@URI. It has been accepted for inclusion in Department of Electrical, Computer, and Biomedical Engineering Faculty Publications by an authorized administrator of DigitalCommons@URI. For more information, please contact digitalcommons-group@uri.edu. 


\title{
WearLight: Towards a Wearable, Configurable Functional NIR Spectroscopy System for Noninvasive Neuroimaging
}

\author{
Manob Jyoti Saikia, Student Member, IEEE, Walter G. Besio, Member, IEEE \\ and Kunal Mankodiya, Member, IEEE.
}

\begin{abstract}
Functional Near-Infrared Spectroscopy (fNIRS) has emerged as an effective brain monitoring technique to measure the hemodynamic response of the cortical surface. Its wide popularity and adoption in recent time attribute to its portability, ease of use, and flexibility in multi-modal studies involving electroencephalography (EEG). While fNIRS is still emerging on various fronts including hardware, software, algorithm, and applications, it still requires overcoming several scientific challenges associated with brain monitoring in naturalistic environments where the human participants are allowed to move and required to perform various tasks stimulating brain behaviors. In response to these challenges and demands, we have developed a wearable fNIRS system, WearLight which was built upon an Internetof-Things (IoT) embedded architecture for onboard intelligence, configurability and data transmission. In addition, we have pursued detailed research and comparative analysis on the design of the optodes encapsulating an NIR light source and a detector into 3D-printed material. We performed rigorous experimental studies on human participants to test reliability, signal-to-noise ratio, and configurability. Most importantly, we observed that WearLight has a capacity to measure hemodynamic responses in various setups including arterial occlusion on the forearm and frontal lobe brain activity during breathing exercises in a naturalistic environment. Our promising experimental results provide an evidence of preliminary clinical validation of WearLight. This encourages us to move towards intensive studies involving brain monitoring.
\end{abstract}

2 Index Terms-NIR spectroscopy, fNIRS, neuroimaging, optode, wearable, wireless, configurable, hemoglobin, embedded system

\section{INTRODUCTION}

Understanding the human brain functionality is among the most far-reaching challenges today. For example, imaging the brain can help to elucidate different clinical manifestation of neurological conditions including Alzheimer's disease, Parkinson's disease, Epilepsy, Schizophrenia, mood disorders, anxiety disorders, and brain injuries [1]-[5]. For decades, brain scanning technologies such as functional magnetic resonance imaging (fMRI) have undoubtedly advanced the science of the brain's functional framework. However, fMRI faces limitations and challenges [2], [4], [6]-[9]:

- Low Temporal Resolution: fMRI has high spatial resolution, producing brain images with the voxel size of 1-2 $\mathrm{mm}^{3}$. However, fMRI has limited temporal resolution which is 1 frame per second.

The authors are with the Department of Electrical, Computer and Biomedical Engineering, University of Rhode Island, RI 02881 USA (e-mail: manob@uri.edu; besio@uri.edu; kunalm@uri.edu

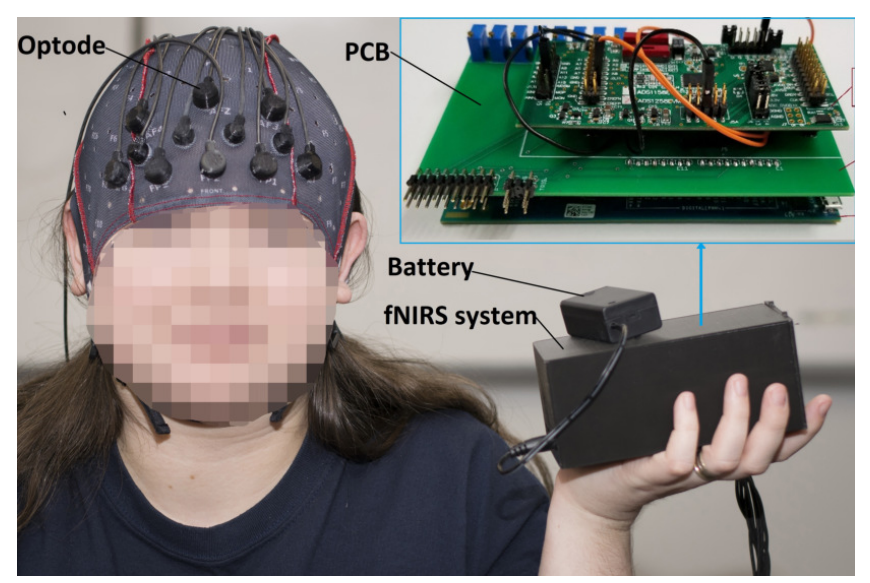

Fig. 1. WearLight fNIRS brain imaging system. A participant wearing optodes on the head using an electrode cap to image prefrontal cortex.

- Non-portability: fMRI is a bulky scanner that requires patients to lay horizontal in a tunnel. fMRI requires a special custom built stationary room.

- Motion Artifact: It is not possible to perform neuroimaging when patients are in their natural positions such as sitting, standing or walking. Additionally, patients are required to stay motionless while undergoing fMRI neuroimaging.

- Non-compatibility: fMRI is not recommended for infants and patients with any ferromagnetic medical implants such as pacemakers, deep brain stimulation (DBS) and some orthopedic implants.

These critical barriers imposed by fMRI motivate the development of other tools which help us to advance the science of the brain's functional architecture. One such tool is functional near-infrared spectroscopy (fNIRS) which is an optical brain imaging technique, based on transmitting NIR light noninvasively from the scalp, and measuring the receiving light passed through the cortex and reflected from the brain [7], [10]-[14]. fNIRS is an emerging tool for neuroimaging that shows promise to address a subset of the limitations associated with fMRI. For example, fNIRS has a comparatively higher temporal resolution than fMRI [2], [8], [15]. fNIRS is safe, portable and flexible in regards to monitoring the human brain that is in its natural state without constraining the participants' posture and motion [9], [16], [17]. 

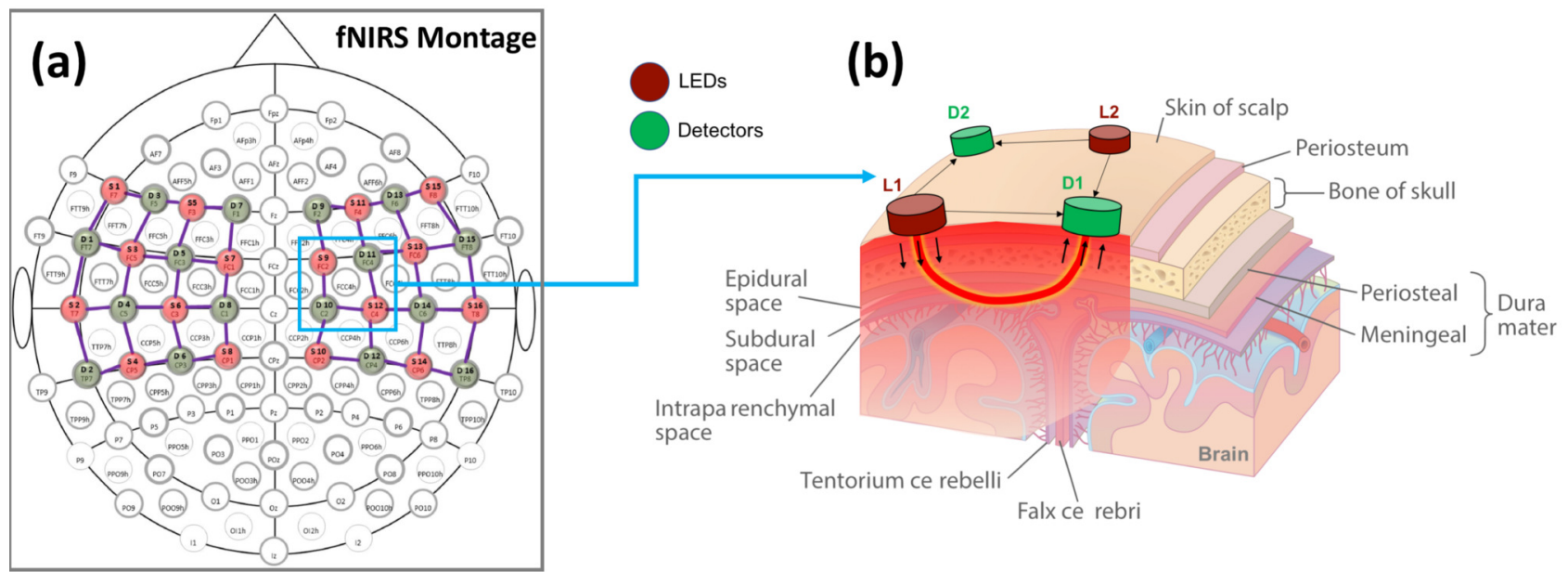

Fig. 2. The basic principle of fNIRS. (a) fNIRS montage cap containing NIR light source and detector arrangements, and (b) propagation of NIR light through different tissue layers of a human head from a source to a detector.

In this article, we present the design and development of WearLight, a wearable fNIRS system aimed at advancing the circuit system architecture of fNIRS [Fig. 1]. The system is low-cost, battery operated with continuous wave near infrared spectroscopy (cw-fNIRS) [4], [7], [13] for real-time monitoring of brains in freely moving humans. The hardware and software were optimized and verified for the functionality, signal quality, and safety. It is also possible to use multiple WearLight systems simultaneously to image brain activities over a large area.

The presented fNIRS system makes the following key contributions:

- Portability \& Wearability: WearLight is a miniaturized fNIRS system made of an embedded controlling unit to provide high-resolution fNIRS data at a frame rate of $11 \mathrm{~Hz}$. WearLight hardware supports up to eight dual wavelength light emitting diodes (LEDs) and sixteen photodiode detectors for the direct illumination and detection respectively. The optodes are placed on the head using a general purpose electrode cap and the portable fNIRS system can be worn on the waist, arm, or other area.

- Wireless \& Configurability: We have designed and developed fNIRS optodes. WearLight provides easy placement of the optodes on the electrode cap, overall low optode-skin contact pressure, electrical isolation, battery operation and optical power within the safe limit. fNIRS channels comprising a source-detector (SD) pair, with adjustable sensitivity. WearLight can be configured wirelessly to set up a montage and also to collect the fNIRS data in real-time.

- Real-time data processing \& visualization: WearLight has the ability to perform data processing and send the data wirelessly to a graphical user interface (GUI) software on a computer. These data processing and displaying services are in real-time.

- Experimental Validation: WearLight is highly stable with respect to the NIR light transmission and detection with an overall low system noise, low channel crosstalk, low drifts and highly sensitive while immune to the background ambient noise. Two sets of experiments, (1) a basic arterial occlusion experiment to measure changes in concentrations of oxy-hemoglobin $\left(\mathrm{HbO}_{2}\right)$ and deoxyhemoglobin $(\mathrm{Hb})$ at the regional muscle, and (2) imaging frontal brain on $(\mathrm{N}=8)$ participants during breathing exercises evaluate the working of the instrument. The typical changes in $\mathrm{HbO}_{2}$ and $\mathrm{Hb}$ during these experiments are presented in the result section of the paper.

The principle and theoretical background of fNIRS are described in Section II-A. The state-of-the-art about fNIRS circuits and systems is described in Section II-B. Section III describes the design of the WearLight fNIRS hardware, involving the detailed explanation of each component. We have performed system-level experiments described in Section IV which involve human participants.

\section{BACKGROUND AND STATE-OF-THE-ART}

\section{A. fNIRS Principle:}

As shown in Figure 2, fNIRS has a close resemblance to EEG, which is another non-invasive brain monitoring method [18]-[20]. Both fNIRS and EEG are very similar in terms of their application and appearance because both use a multielectrode setup covering the scalp to capture the brain activity. The fundamental difference is that fNIRS measures hemodynamic response (pertaining to the dynamics of the cerebral blood oxygenation) while EEG measures the electrical activity of the brain. fNIRS measures changes in chromophore concentration, oxy-hemoglobin $\left(\mathrm{HbO}_{2}\right)$ and deoxy-hemoglobin $(\mathrm{Hb})$ in response to the human brain functions non-invasively [10], [21]-[23]. Multi-wavelength near-infrared (NIR) light sources are employed to shine light on the scalp of human head that enables propagation of the light through the tissue. Each wavelength is absorbed by the chromophores differently [24]. Figure 3 presents the absorption spectra of two important chromophores $\mathrm{HbO}_{2}$ and $\mathrm{Hb}$ for the fNIRS brain imaging. Typically light detectors are used at a distance of 25-40 $\mathrm{mm}$ away from the corresponding NIR light source to detect 
the back-reflected diffused light [25]-[29] from the cortical surface of the brain, on the scalp surface.

Figure $2 \mathrm{~b}$ presents the sketch of the cross-sectional distribution of light path in the tissue in a human head. Incident NIR light onto the scalp is scattered and absorbed as it propagates through the scalp, skull, cerebrospinal fluid (CSF), gray matter, and brain, and is detected by a detector on the scalp surface. The detected light intensity variations, at least at two wavelengths, can be used to compute the changes in concentrations of $\mathrm{HbO}_{2}$ and $\mathrm{Hb}$ in response to the activation in the cerebral cortex of the brain. A source-detector (SD) pair can detect brain activity at around the midpoints of the SD pair creating an fNIRS channel. Multiple SD pairs can be used to create large numbers of fNIRS channels to cover the whole brain. Often the fNIRS channels are time, frequency and/or spatially multiplexed in order to simultaneously measure possible fNIRS channels to increase the frame rate of the imaging [14], [17], [30]. Using high density (HD) fNIRS measurement, it is also possible to reconstruct 3D distributions of the chromophore concentration of the brain [25], [31] [33]. Among the three fNIRS implementations, time-resolved, frequency domain and continuous wave $(\mathrm{cw})$ technique, $\mathrm{cw}$ fNIRS based on using constant amplitude NIR light intensity is the most practical for portable brain imaging for its simplicity [12], [17], [34]-[37].

The Modified Beer-Lambert Law (MBLL) is the most commonly employed mathematical model to estimate the relative changes in hemoglobin $\left(\triangle H b O_{2}\right.$ and $\left.\Delta H b\right)$ concentration [11], [23], [38], [39].

The oxy-hemoglobin and deoxy-hemoglobin concentration changes, $\Delta \mathrm{HbO}_{2}$ and $\Delta \mathrm{Hb}$ can be calculated as [23], [40], [41],

$$
\begin{gathered}
\Delta H b O_{2}=\frac{\alpha_{H b}^{\lambda_{1}} \frac{\Delta A^{\lambda_{2}}}{L^{\lambda_{2}}}-\alpha_{H b}^{\lambda_{2}} \frac{\Delta A^{\lambda_{1}}}{L^{\lambda_{1}}}}{\alpha_{H b}^{\lambda_{1}} \alpha_{H b O_{2}}^{\lambda_{2}}-\alpha_{H b}^{\lambda_{2}} \alpha_{H b O_{2}}^{\lambda_{1}}} \\
\Delta H b=\frac{\alpha_{H b O_{2}}^{\lambda_{1}} \frac{\Delta A^{\lambda_{2}}}{L^{\lambda_{2}}}-\alpha_{H b O_{2}}^{\lambda_{2}} \frac{\Delta A^{\lambda_{1}}}{L^{\lambda_{1}}}}{\alpha_{H b O_{2}}^{\lambda_{1}} \alpha_{H b}^{\lambda_{2}}-\alpha_{H b O_{2}}^{\lambda_{2}} \alpha_{H b}^{\lambda_{1}}}
\end{gathered}
$$

where $\alpha, A$ and $L$ are molar absorption coefficients, attenuation of light and mean path length of detected photon respectively measured at two wavelengths $\lambda_{1}$ and $\lambda_{2}$.

\section{B. State-of-the-art: fNIRS System Design}

Typically, an fNIRS system consists of a table-top instrument connected to a desktop computer and optical fibers with a montage cap. The instrument is controlled by a computer software and the montage cap interfaces human brain to the fNIRS system. These fNIRS systems are mostly operated in the laboratory environment for neuroscience research. Although optical-fiber-based fNIRS systems have some advantages for emitting and collecting light, they limit the human's movements and the fibers exacerbate motion artifacts contamination. While the spatially restrained settings are feasible for bedside monitoring, they hamper imaging of a brain while participants perform natural physical activities or imaging an infant [12], [16], [30].

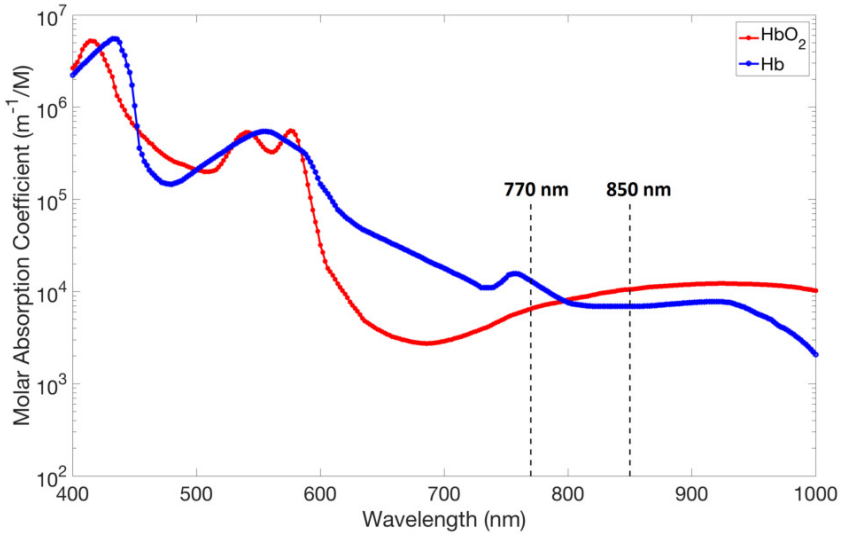

Fig. 3. The plot of absorption spectra of oxy-hemoglobin $\left(\mathrm{HbO}_{2}\right)$ and deoxy-hemoglobin $(\mathrm{Hb})$ of tissue, represented in terms of molar absorption coefficients. Experimental data were taken from OMLC [24]. The wavelengths of the LEDs used for our fNIRS system are indicated by the vertical dashed line.

To overcome these constrains, a new generation of wireless fNIRS systems that can be worn and carried by the participant is desirable. To achieve a wearable fNIRS system, it needs to be a low-power battery-operated wireless system. The system is required to be small and lightweight, while providing a greater number of optodes and their corresponding fNIRS channels, without sacrificing the frame rate of the system $(>6$ $\mathrm{Hz}$ preferable). Also, the sensitivity and dynamic range of the system needs to be high enough to support a wide range of $\mathrm{SD}$ distances $(2 \mathrm{~cm} \leq \mathrm{SD}$ distance $\leq 4 \mathrm{~cm})$ and to detect very low intensity optical signals when the SD distance on the hairy head is greater. If the wearable fNIRS system is compatible with EEG, it can provide the added benefit of multi-modal imaging. Additionally, real-time configurability, control, data acquisition, data processing and displaying results are beneficial.

In recent years, research and publications on fNIRS brain imaging are growing [7]. However, most of are based on clinical aspect of the fNIRS system [2]-[5], [8], [16], [19], [20], data analysis [39], [42], [43] and its usage in BCI applications or neuroimaging [9], [13], [34], [44]-[46]. Some studies on the hardware aspect of the fNIRS system have been published recently [35], [37], [47]-[52] and increasing interest in multi-channel portable fNIRS systems are observed. There are few studies that have attempted development for portable wearable fNIRS brain imaging to free up the participant's head position [17], [30], [35], [36], [50], [53], [54]. These systems certainly have some advantages. However, each of them suffers three to seven drawbacks: (1) few fNIRS measurement channels, (2) low frame rate, (3) low dynamic range (ADC bit resolution), (4) incompatible for EEG electrode placement, (5) less sensitive ( $\leq 3 \mathrm{~cm}$ SD separation), (6) suitable only for limited regions of the head, or (7) heavy to carry around with the wire connected PC, as listed in the Table II in the section V.

\section{WEARLIGHT FNIRS SYSTEM DESIGN}

An fNIRS system that can monitor brain functional activities continuously in an unconstrained manner, requires the 


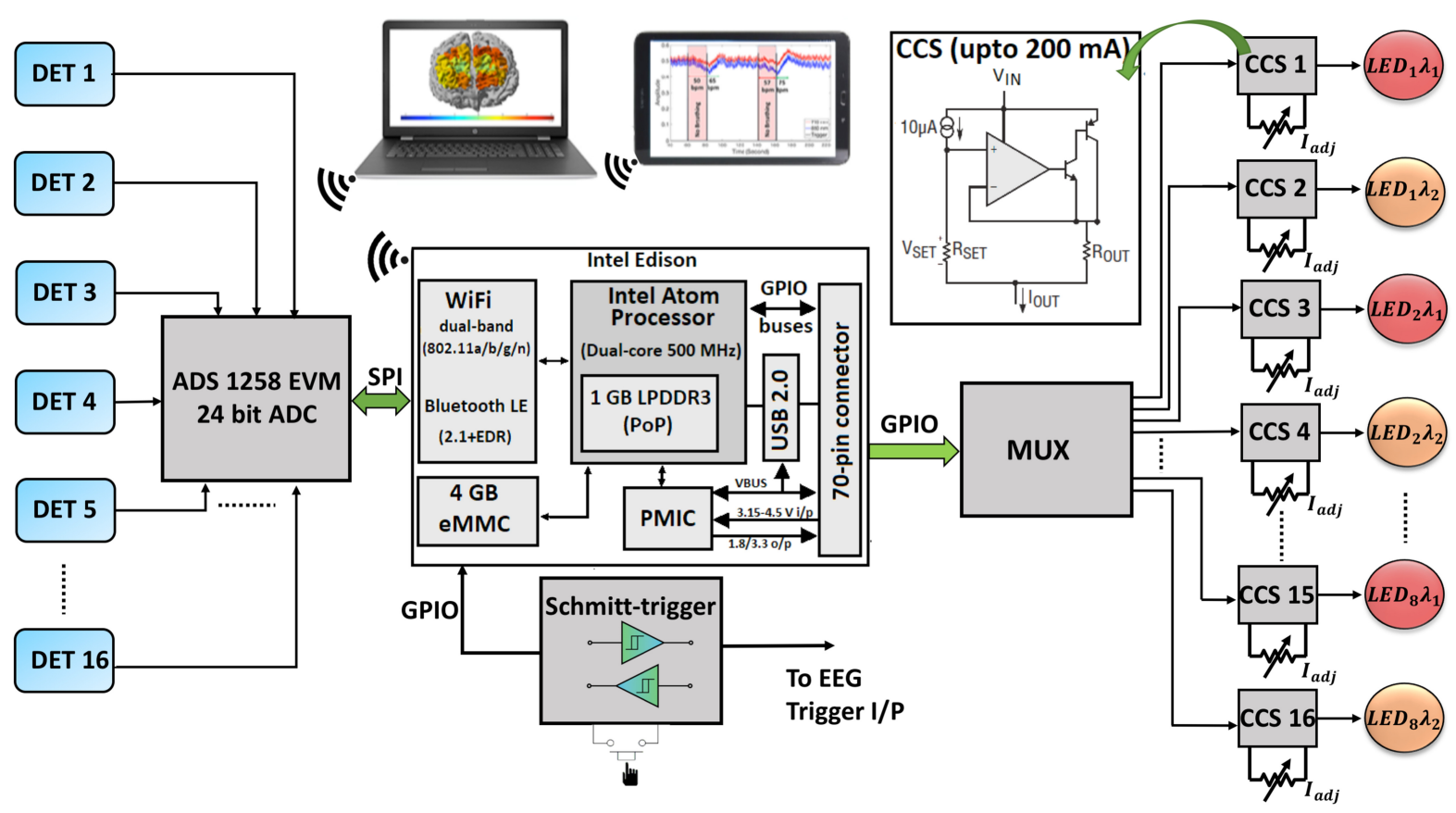

Fig. 4. A simplified block diagram showing the hardware components of the WearLight fNIRS system. A single WearLight module supports eight dual wavelength LEDs and sixteen detectors.

system to have a small form factor, easily wearable, light, configurable, and battery-operated and preferably wireless. As the number of fNIRS channels increases in the system, meeting these hardware requirements for such a system for the long-term brain monitoring becomes challenging. In addition, for a multi-channel portable wireless fNIRS system, the real-time configuration, and data transmission, processing and visualization are demanding. However, the multi-channel fNIRS system has the advantage of topographic imaging of an overall large portion of the brain that provides the opportunity for comprehensive neuroscience studies.

In this research, we have focused on the development of a multi-channel fNIRS system, WearLight with the capabilities of wireless connectivity and configurability while the participant wears the system. It is intended to be a portable system that can be used during physical activities or at rest. In order to achieve this goal, we have developed a modern fNIRS hardware incorporating the Intel Edison embedded computing platform that enables us to configure, operate and acquire data wirelessly to monitor hemodynamic states of the brain in realtime.

Our software architecture connects to our fNIRS hardware system using a computer or Android tablet through WiFi and interacts to send configuration settings for the montage and also to receive fNIRS data. The architecture of the WearLight fNIRS system comprises three distinctive parts: fNIRS control unit, a set of optodes along with a montage cap, and a data processing unit (computer/tablet).

Figure 4 presents the main functional units of our fNIRS system. Figure 1 shows a participant holding the control unit and optodes on the head. The optode montage cap holds the light sources aFnd detectors in an appropriate geometry on the region of the brain intended to be monitored. The optodes are interfaced to the control unit via a bundle of flexible biocompatible electric cables using a dedicated connector. The fNIRS control unit can handle up to 8 dual-wavelength LEDs and 16 detectors creating maximum of $8 \times 16=128$ fNIRS channels. However, the usable channels are decided by the optode's placement on the montage cap that consists of a combination of light sources and detectors, and the SNR of the fNIRS channels.

A host computer, as a data processing unit, connects to the fNIRS control unit via authentication and performs bidirectional communication to synchronize the operations such as switching the light sources, optical measurements at two wavelengths, data transmission, fNIRS data processing and hemodynamics response visualization. In addition, the control unit saves optical raw measurement data in a file in its own memory for the future use.

\section{A. fNIRS CONTROLLING UNIT}

The portable fNIRS controlling unit is the core of WearLight. To minimize noise and electrical crosstalk between analog signals, and analog and digital circuits, and electrical safety, the hardware is a multi-layer and multi-power supply architecture. This modular approach helps in testing and debugging, as well as for the future hardware upgrades. We have fabricated three such fNIRS controlling units. They can be operated independently or configured to work together in a synchronized manner to increase the fNIRS channel count.

Each fNIRS controlling unit consists of three printed circuit boards (PCBs) sandwiched together: (1) embedded system PCB, (2) analog circuit PCB and (3) digitization PCB. It also has a dedicated power supply for each PCB. The fNIRS controlling unit is enclosed in a $3 \mathrm{D}$ printed box $(13.5 \times 6 \times 8.4$ 
$\mathrm{cm}^{3}$ ) having access to all of the connector ports [Fig. 1]. The user can wear this unit using a waist or arm band. Optodes from the montage cap and battery are connected to the control unit through two separate connectors. Once powered ON the fNIRS system boots up and goes to idle mode. A computer or a tablet can be used to connect to the control unit wirelessly in order to send the command to start the fNIRS data collection and to visualize data in real-time wirelessly.

1) Embedded System PCB: The bottom-most PCB of the fNIRS controller consists of an Intel Edison System on Chip (SoC) $\left(3.55 \times 2.5 \times 0.39 \mathrm{~cm}^{3}\right)$ along with the necessary peripheral devices and interfaces. We have chosen the Edison for its small form factor, low-power consumption, multiple connectivity options, and availability of a broad set of $\mathrm{I} / \mathrm{O}$ support, while a powerful computational capability for the wearable device.

The embedded system is the heart of the controller that is responsible for the synchronization of the tasks of the fNIRS system. It connects to a host computer wirelessly and communicates back and forth throughout the fNIRS data acquisition. The embedded system performs the high speed bi-directional digital data communication with the analog to digital converter (ADC) present on the digitization PCB. The embedded system sends the ADC configuration settings and reads 32 bit (24 bit ADC and 8-bit status) data at every measurement event. It also performs basic digital data conversion, processing, formatting, wireless data transmission to the host computer and stores data in a file for future use. Thus the WearLight fNIRS system works as an IoT device having the capability of real-time configurability, control, data acquisition, data processing and displaying results. The Intel Edison, as a single board computer in the WearLight system also computes $\triangle \mathrm{HbO}_{2}$ and $\Delta \mathrm{Hb}$ in real-time. However, we perform intensive data processing in our MatLab based GUI software in the host computer for better performance. The host computer acquires data wirelessly and performs basic data processing simultaneously to display $\triangle \mathrm{HbO}_{2}$ and $\mathrm{\Delta Hb}$ in real-time. Advanced data analysis processing, such as removal of the noise, correction of motion artifact and baseline shifting etc., and topographic plots are performed offline in the host computer.

2) Analog Circuit PCB: The middle PCB has the circuitry for the constant current source (CCS), multiplexer, current adjustment $\left(I_{a d j}\right)$, high-speed sync out and trigger. This PCB also routes the bottom digitization PCB to the top embedded system PCB. The analog circuit PCB contains connectors for the optodes, trigger input switch, and trigger out.

The analog circuit PCB contains the circuitry for the LED current driver to adjust the current accurately for each LED at each wavelength. Figure 4 also shows the circuit diagram of the CCS that provides current regulation within $10 \mathrm{ppm} / \mathrm{V}$. The potentiometer $\left(R_{S E T}\right)$ on the analog PCB as shown in figure 3 , serves to adjust the constant current $\left(I_{a d j}\right)$ for the LEDs to emit a stable optical power $(<5 \mathrm{~mW})$ within the safe range [55]. The current can be set between $0.5 \mathrm{~mA}$ and $200 \mathrm{~mA}$. We have used a low ON resistance and low OFF leakages 16channel analog multiplexer (CD74HC4076) to bias and switch the CCS of the LEDs. The regulated current from the CCS is

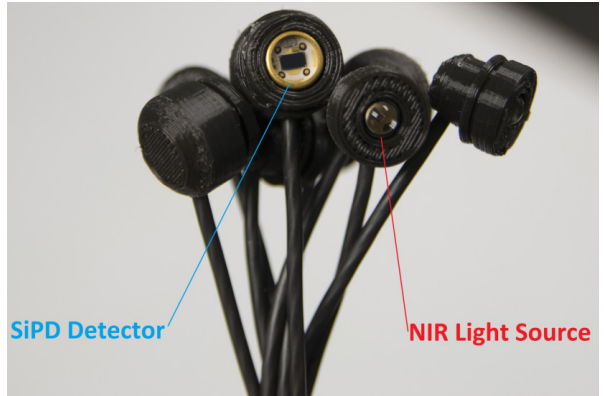

Fig. 5. 3D printed optode design. Optodes made of multi-wavelength LEDs (MTMD7885NN24) and Si-PD detectors (ODA-6WB-500M detectors).

given by $I_{O U T}=10 \mu A \times R_{S E T} / R_{O U T}$, which is independent of the variation in the supplied bias voltage. Hence, resistors with the same temperature coefficient, in the resistor network allow us to apply a regulated current independent to the other circuit variabilities. The analog circuit PCB can handle up to 16 CCSs.

3) Digitization PCB: The topmost PCB consists of an ADC along with its necessary circuit components to test and configure the rate of digitization and data transfer with the embedded system. We have used a 24-bit Delta-sigma $(\Delta \Sigma)$ ADC from Texas Instrument (ADS1258). The ADC utilizes the fourth-order modulator followed by a fifth-order sinc digital filter optimized for the low-noise performance. We configured the ADC for 16 single-ended inputs so that a single fNIRS module supports up to 16 detectors. This top data acquisition digitization PCB communicates with the bottom embedded system via serial digital communication, SPI (Serial Peripheral Interface).

\section{B. OPTODES (NIR LIGHT SOURCE and DETECTOR)}

The optodes for fNIRS are of two types: 1) the NIR light sources at multiple wavelengths and 2) light detectors to receive the back-reflected light from the brain. The optodes are the interface between the scalp surface and the fNIRS hardware. The optodes are the most critical parts of the fNIRS system since the overall signal quality of the fNIRS imaging greatly relies on the type of optodes used, proper optodes-scalp coupling, and the electrical stability. The human scalp has an irregular geometry having a curved surface. The coupling of the optodes to the scalp through the hair is challenging, as the source optodes must be placed orthogonally to the scalp surface in order to maximize the injection of the NIR light through the tissue and to prevent leakage of direct NIR light to the neighboring detectors. Similarly, the detectors should also be orthogonal to the scalp surface only to collect the back scattered NIR light from the deep tissue, isolating the possible direct ambient and NIR light from the neighboring source. At the same time, the participant should feel comfortable wearing the optodes for brain monitoring experiments that tend to run for a significant period of time.

Often detectors get saturated or the signal to noise ratio (SNR) level plummets due to poor coupling of the optodes to the scalp or motion artifacts [39], [42]. In that case, the severely affected fNIRS channels need to be discarded from 
further data processing. In WearLight, we have adopted an optical fiberless optodes design that requires less electric power in order to work with the battery operated fNIRS control unit for long-term brain monitoring. Therefore, we use dual wavelength LEDs as an NIR source and photodiode as a detector for our optode design. The LEDs and detectors are housed in a 3D printed holder so that optodes can be appropriately placed on a montage cap and detached easily. This also helps for the multi-modal EEG-fNIRS imaging, where both the EEG electrodes and fNIRS optodes are required to be placed at the same time using a common montage cap [18], [43], [51]. Detectors are positioned $30-40 \mathrm{~mm}$ away from the source in order to receive fNIRS signals from the cortical surface of the brain.

Motion artifact in fNIRS brain imaging is unavoidable. Head movement causes a decoupling of the optode and scalp, resulting in high-frequency spike and baseline shifting of the measured signal. This problem is sometimes solved by simply rejecting all the trials where the motion artifacts are dominant. However, in case of an infant, clinical patient and children, where the number of trials is limited, and fNIRS brain imaging of a freely moving subject, rejection of trials might not be feasible. Hence, intensive post-processing is performed in order to remove motion artifact from the measurements using the inherent characteristics of the amplitude and frequency of the signal due to the artifact. Many post-processing approaches are proposed to correct for motion artifacts and each of them has their own benefits [56]. Some of them are principal component analysis (PCA) [57], independent component analysis (ICA) [58], Kalman filtering [59], correlation-based signal improvement (CBSI) [60], wavelet filtering [61] and spline interpolation [62].

1) Light sources - LEDs: We use LEDs as the NIR light source over lasers. The broader emission spectra $(\Delta \lambda=35$ $\mathrm{nm})$ as opposed to the sharp peaked laser diode $(\Delta \lambda=1 \mathrm{~nm})$ and the incoherent and uncollimated optical output of these LEDs make the use of LED safe, allowing direct contact with the skin. Also, the power consumption of LEDs is much less than the laser source. On the other hand, laser light sources often require temperature monitoring and cooling systems to remove extreme heating of the semiconductor junction and optical fibers to carry light to tissue. Furthermore, the operation of lasers demands additional care as it can cause potential injuries to eyes. Hence, LEDs are appropriate for our portable battery operated fNIRS system that reduces the overall system cost and hardware requirements while making the optode design compact. Also, LEDs as an NIR source are suitable for brain monitoring of vulnerable population of newborns.

We have designed source optodes using three wavelengths (750, 810 and $850 \mathrm{~nm}$ ) LED package MTMD7885NN24 from Marktech Optoelectronics. We have selected two wavelengths 750 and $850 \mathrm{~nm}$ out of the three available wavelengths. The spectral half width $(\Delta \lambda)$ of both 770 and 850 wavelengths are $35 \mathrm{~nm}$. These two wavelengths are sufficient to resolve concentrations of two chromophores, $\mathrm{HbO}_{2}$ and $\mathrm{Hb}$. Also, crosstalk between these two wavelengths is less significant with respect to other wavelengths combinations as seen in
Figure 3. Although $\Delta \lambda$ is wider compared to the diode lasers, $35 \mathrm{~nm}$ is narrow enough to resolve two chromophores, since absorption spectra are relatively flat around these wavelengths [vertical dashed line shown in Figure 3]. Also, the isosbestic point, $810 \mathrm{~nm}$ lies between $770 \mathrm{~nm}$ and $850 \mathrm{~nm}$, at which $\mathrm{HbO}_{2}$ and $\mathrm{Hb}$ have identical absorption coefficients as evident from Figure 3. The LED driving current is set by CCS as described in section III-A2 such that the maximum optical power is below $5 \mathrm{~mW}$ when the LED is ON.

2) Photodetectors: We use silicon photodiode (Si-PD) detectors, ODA-6WB-500M (Opto Diode Cop.) to detect the optical signals that are reflected from the cortex and other tissues. Si-PD detectors do not need the high voltage supplies that an avalanche photodiode (APD) or photomultiplier tube (PMT) detectors do. Also, Si-PDs are smaller and cost-effective for covering a large portion of the head. They are also suitable for high-speed fNIRS data collection for higher imaging frame rates. The ODA-6WB-500M has high responsivity of about $250 \mathrm{~V} / \mu \mathrm{W}$. It has a cylindrical package which is convenient for fabricating holders for the cap.

We have designed 3D printed LED and detector holders such that the optodes can be easily attached and detached from the montage cap. The circuitry and connections are housed in the internally shielded optode holders. This feature allows us to configure the optode locations on the head depending on the imaging area and experimental protocol and to place the optodes alongside the EEG electrodes. Figure 5 shows the final version of the optode based on dual-wavelength LEDs and ODA-6WB-500M used for our experimentation.

In fNIRS brain imaging, recording high SNR fNIRS signals from the subject's head covered with dense, thick and dark hair is challenging. If the optodes are designed on a sensor pad [30], [35]-[37], [50], [53], [54], placement of optodes on the hairy head is even more challenging. This design also inhibits placement of EEG electrodes alongside the fNIRS optodes. Our optodes are discrete elements and the overall sensitivity of the WearLight's fNIRS channels are high, that allow us to place optodes on the hairy head beside EEG electrodes to collect EEG and fNIRS signals simultaneously. We use watersoluble gel to keep hair pushed out of the way to enhance the optode-scalp coupling. Thus our lightweight fiberless optode (3.6 gm per optode with the connecting cable) improves coupling the sources and the detectors to the head and provides a better comfort level for long-term brain monitoring. Also, this design suffers from fewer motion artifacts compared to optical fiber based optode.

The effective quantization signal to noise ratio (SNR) of the WearLight hardware is $131.8 \mathrm{~dB}$ and the noise level is 2.8 $\mu V_{R M S}$. However, the SNR of each fNIRS channels during an experiment depends on various factors such as LED light intensity and wavelength, SD distance, noise equivalent power (NEP) of the detector, physiological noise, ambient noise, sampling rate, skin tone, thickness and color of hair and optode-scalp coupling. We have experimentally evaluated the achievable true SNR of the WearLight's fNIRS channels. In a typical experiment, SNR of the individual fNIRS channels varies between $32 \mathrm{~dB}$ and $70 \mathrm{~dB}$ depending on the mentioned factors. WearLight helps to improve SNR of the fNIRS chan- 
nels by using the GUI software that displays computed SNR of the individual fNIRS channels during the initial calibration process prior to the actual experiment. It allows us to visualize the coupling status and overall noise level of all the channels. We adjust for the optimum scalp coupling, and to maximize the SNR of all fNIRS channels in the calibration process in order to achieve a maximum number of usable fNIRS channels. We also examine the presence of the photoplethysmographic signal (due to the cardiac cycle) superimposed on the fNIRS signal to verify the effective coupling of the optode to the scalp. We suggest WearLight user to use another layer of opaque head cap on the optode cap to minimize the influence of background radiation if it is necessary.

\section{REsults}

We have performed a basic and a more complex experimental evaluation of the WearLight fNIRS system on $\mathrm{N}=8$ participants. The first experiment was to monitor the changes in hemoglobin concentration of regional muscle. We have compared our results with the results published by other researchers to verify the working of WearLight. The second experiment involved imaging prefrontal cortex of participants performing breathing exercises. This experiment allowed us to image the hemodynamic response of the brain in response to the breathing exercise. Also, the observed heart rate variation patterns, superimposed on the fNIRS signal, supported the expected heart rate variation in the breathing exercises.

We have used MBLL [11], [23], [38], [40], [41] and Equ. 1 to compute $\triangle \mathrm{HbO}_{2}$ and $\mathrm{Hb}$ over time. The raw fNIRS measurement data from the brain carries other physiological noises such as heart beat $(1 \sim 1.5 \mathrm{~Hz})$, respiration $(0.2 \sim 0.5$ $\mathrm{Hz})$ and Mayer waves $(\sim 0.1 \mathrm{~Hz})$ etc. Hence, we have used second-order Butterworth band-pass filter, $\left(f_{\text {cutof } f \text {.low }}=0.01\right.$ $\mathrm{Hz}$ and $f_{\text {cutof } f, h i}=0.25 \mathrm{~Hz}$ ) to remove these noises present in the fNIRS signal.

\section{A. Experiment 1: Arterial occlusion experiment}

The first experiment with the WearLight fNIRS system was to measure the changes in hemoglobin concentration at the regional muscle (forearm) due to the arterial occlusion. This experiment evaluates the working of the hardware and software of our fNIRS system. An optode pair was placed on the forearm as shown in Figure 6 (a). Since the forearm tissue is more transparent than the scalp tissue, this experiment requires less optical power from the LED in order to set the detector in the middle of the dynamic range. A sphygmomanometer cuff was rapidly inflated to $180 \mathrm{mmHg}$ around the upper arm, just above the elbow to exclude blood flow to the hand for not more than 120 seconds for the participant's comfortability. As evident from the time interval between the occurrences of two trigger events corresponds to the starting and ending of occlusion respectively as shown in Figure 6 (b). Figure 6 (b) also presents the changes in hemoglobin concentration, oxy-hemoglobin $\left(\mathrm{HbO}_{2}\right)$ and deoxy-hemoglobin $(\mathrm{Hb})$ of eight participants (dashed lines) over time, derived from the raw experimental data collected from eight participants. The mean response of the $\left(\mathrm{HbO}_{2}\right)$ and $(\mathrm{Hb})$ changes are presented with
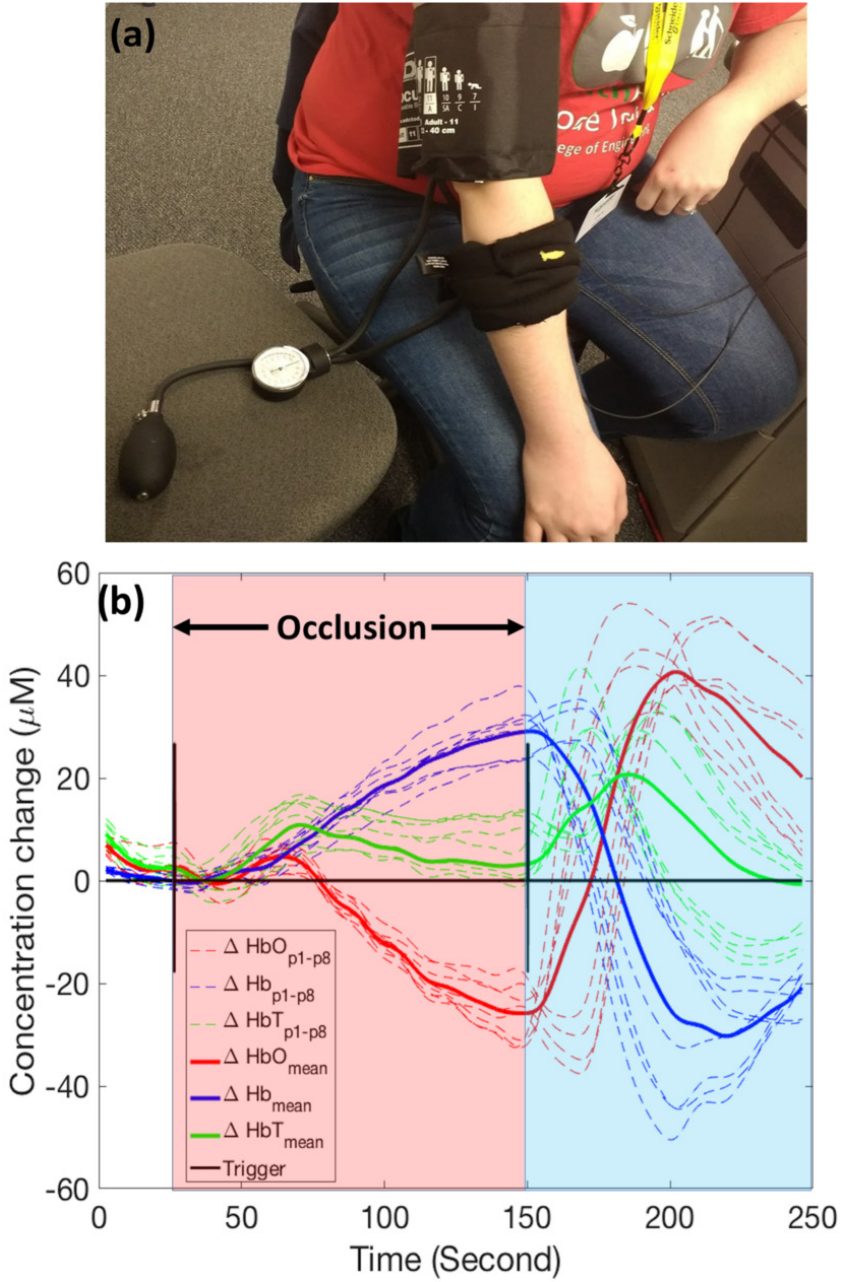

Fig. 6. (a) Experimental set-up for arterial occlusion experiment, a participant is wearing a pair of optodes and sphygmomanometer cuff, and (b) forearm muscle response during arterial occlusion experiment. $\Delta H b O_{p 1-p 8}$, $\Delta H b_{p 1-p 8}$ and $\Delta H b T_{p 1-p 8}$ are the results from the participant no. 1 to participant no. 8 respectively and $\Delta H b O_{\text {mean }}, \Delta H b_{\text {mean }}$ and $\Delta H b T_{\text {mean }}$ are the mean response in the experiment.

bold solid lines. This result depicts the decrease in $\mathrm{HbO}_{2}$ concentration and a simultaneous increase in $\mathrm{Hb}$ concentration due to depletion of locally available hemoglobin in the forearm after trigger event 1 . It is also apparent that the release of the occluding cuff, after trigger event 2 , blood volume increases rapidly, resulting in an increase in $\mathrm{HbO}_{2}$ concentration and a quick washout of $H b$. We have also observed that the trend of the hemoglobin concentration changing shown in our result is similar to the result published by Shang et al. [63], where the measurements were taken using a portable diffuse correlation spectroscopy (DCS) system on the calf muscle during occlusion. The maximum total hemoglobin concentration change (Max. $\Delta H b T$ ) in this experiment (Exp. 1) for the eight subjects are also presented in Table I.

\section{B. Experiment 2: Prefrontal cortex fNIRS experiment}

The experimental setup for imaging prefrontal cortex of the brain using our fNIRS system on 8 participants was similar to the placement of optodes on the head as shown in Figure 1. 


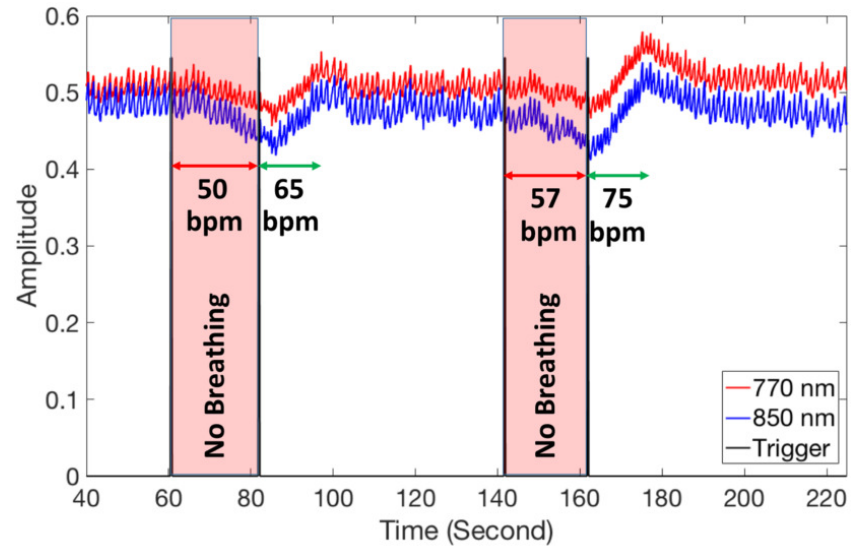

Fig. 7. An experimental raw fNIRS data channel during breathing experiment, collected from a participant.

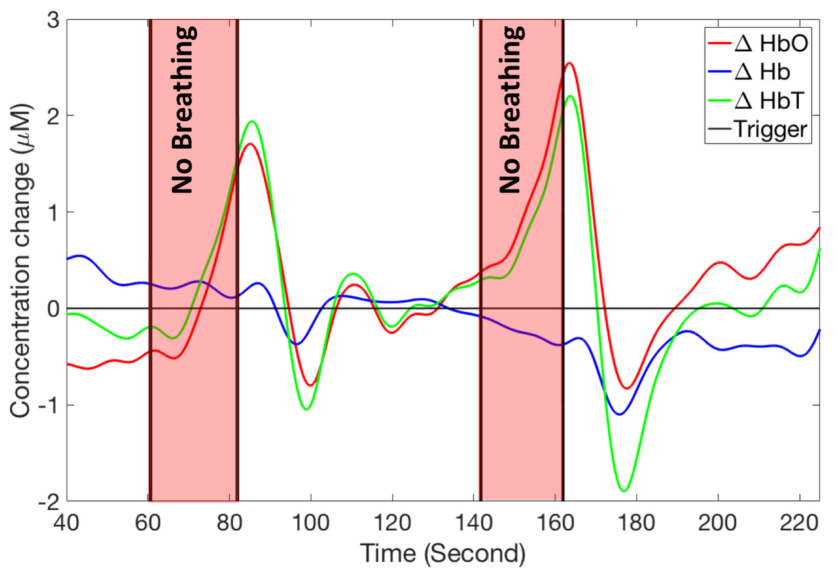

Fig. 8. Hemodynamic response derived from the experimental fNIRS data channel shown in the Figure 7.

The participants wore four pairs of fNIRS optodes to cover the prefrontal cortex area of the brain. Participants were trained and asked to perform breathing exercises. The experimental protocol involved performing relaxed deeper breathing for about 60 seconds and after an occurrence of the first trigger, participants were asked to perform breath retention after the exhalation was complete. The no breath period lasted for about 20 seconds depending on the participants' comfortability level. After the end of no breath period, a second trigger event occurred and the participants started breathing again. The time interval between the two vertical trigger lines in Figures 7 and 8 , represents the no breathing periods. This was continued for several cycles. Figure 7 shows the plot of raw experimental data from an fNIRS channel, collected from a participant that contains signals from both the wavelengths 770 and $850 \mathrm{~nm}$.

We have observed that the raw experimental data from the prefrontal cortex also carried the pulsation caused by heart beats along with the fNIRS signal. Hence, we have also incorporated estimation of heart rate variability (HRV) from these pulse waves in our studies. As shown in Figure 7, at the first no breathing period of 17.9 seconds, 15 peaks were detected corresponding to a slow heart rate of 50 beats per minute (bpm), whereas at the beginning of next start
TABLE I

TOTAL HEMOGLOBIN CONCENTRATION CHANGE $(\Delta H b T)$ IN THE FOREARM OCCLUSION EXPERIMENT (EXP. 1), AND $\triangle H b T$ AND BPM CHANGES IN BREATHING EXPERIMENT (EXP. 2) FOR THE EIGHT SUBJECTS.

\begin{tabular}{|c|c|c|c|c|}
\hline $\begin{array}{c}\text { Participant } \\
\text { No. }\end{array}$ & $\begin{array}{c}\text { Exp. 1 } \\
\text { Max. } \Delta H b T \\
(\mu M)\end{array}$ & $\begin{array}{c}\text { Exp. 2 } \\
\text { Max. } \Delta H b T \\
(\mu M)\end{array}$ & $\begin{array}{c}\text { Exp. 2 } \\
\text { Min. } \\
\text { BPM }\end{array}$ & $\begin{array}{c}\text { Exp. 2 } \\
\text { Max. } \\
\text { BPM }\end{array}$ \\
\hline 1 & 45 & 4 & 50 & 75 \\
\hline 3 & 36 & 4.4 & 59 & 81 \\
\hline 3 & 46 & 4.9 & 55 & 79 \\
\hline 4 & 30 & 3.1 & 49 & 76 \\
\hline 5 & 32 & 3.8 & 52 & 73 \\
\hline 6 & 33 & 4.2 & 57 & 80 \\
\hline 7 & 54 & 4.5 & 60 & 81 \\
\hline 8 & 29 & 2.8 & 51 & 74 \\
\hline
\end{tabular}

breathing period of 13.8 seconds, 15 peaks were observed that corresponds to an increased heart rate of $65 \mathrm{bpm}$. Similarly, $57 \mathrm{bpm}$ and $75 \mathrm{bmp}$ heart rates were observed for the second stop and start breathing period respectively.

We have calculated relative changes in oxy-hemoglobin $\left(\Delta \mathrm{HbO}_{2}\right)$ and deoxy-hemoglobin $(\Delta \mathrm{Hb})$ in the prefrontal cortex from all of the raw intensity measurement data channels using our custom MatLab based fNIRS software. Figure 8 presents the hemodynamic response in the prefrontal cortex computed from a raw experimental fNIRS data channel shown in Figure 7, in response to the breathing exercise over time. We have observed that the concentration of the $\mathrm{HbO}_{2}$ is slowly increased in the two no breathing periods. This reveals the low oxygen consumption in the brain in the no breathing periods after a relaxed deep breathing period. The concentration of the $\mathrm{HbO}_{2}$ slowly settled down to the baseline after the start breathing periods. When a normal person performs physical exercises, carbon dioxide $\left(\mathrm{CO}_{2}\right)$ in the blood increases. As a result, heart rate goes up to supply more oxygen $\left(\mathrm{O}_{2}\right)$ in the blood. However, in our experiment during the meditative breathing state, our mind and body relaxed more and relaxed muscles no longer needed as much $\mathrm{O}_{2}$. As a result, the $\mathrm{CO}_{2}$ level decreased. During this state, a no breathing period further relaxed the participants resulting in reduced heart rate and a positive $\mathrm{\Delta Hb \textrm {O } _ { 2 }}$ change in the brain [64]-[67]. We have also observed that overall reduction of $H b$ concentration in the course of breathing exercise and two dips of $\mathrm{Hb}$ after the beginning of start breathing periods when the participant breathed rapidly in a high BPM.

The fNIRS imaging provides relative changes of hemoglobin concentration, and hemodynamic responses vary with the subject and the experimental conditions. The maximum total hemoglobin change (Max. $\Delta H b T$ ), and the estimated maximum and minimum heart-rate (Max. BPM and Min. BPM) in this experiment (Exp. 2) for the eight subjects are presented in the Table I.

We have also topographically mapped $\mathrm{HbO}_{2}$ and $\mathrm{Hb}$ concentration changes on a 3D cortical brain surface offline combining all the fNIRS channels that cover the prefrontal 

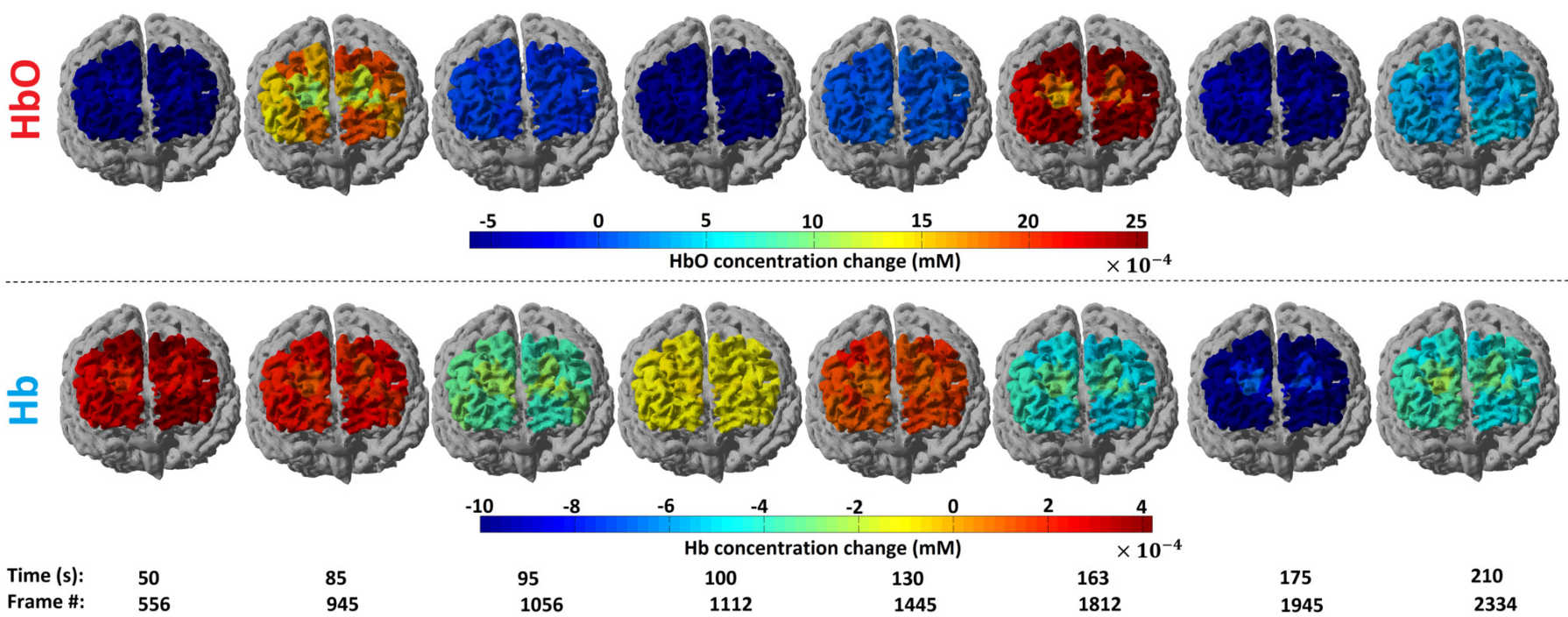

Fig. 9. Topographic map of $\mathrm{HbO}_{2}$ and $\mathrm{Hb}$ concentration changes on a 3D cortical surface of the brain at different important time frames from the experimental fNIRS data collected from a participant during the breathing exercise using our WearLight fNIRS system.

TABLE II

CHARACTERISTICS OF PORTABLE FNIRS TECHNOLOGIES.

\begin{tabular}{|c|c|c|c|c|c|c|c|c|c|}
\hline Author, year & $\begin{array}{c}\text { Architecture/ } \\
\text { Embedded computing }\end{array}$ & $\begin{array}{l}\text { No. of Source } \\
\text { /Detector/SD } \\
\text { distance/Type }\end{array}$ & $\begin{array}{l}\text { EEG } \\
\text { compa- } \\
\text { tibility }\end{array}$ & $\begin{array}{l}\text { Wireless } \\
\text { capability }\end{array}$ & $\begin{array}{l}\text { Real-time } \\
\text { processing }\end{array}$ & $\begin{array}{l}\text { Frame } \\
\text { rate } \\
(\mathrm{Hz})\end{array}$ & $\begin{array}{c}\mathrm{ADC} \\
\text { (bit) }\end{array}$ & $\begin{array}{l}\text { Wearable } \\
\text { system/ } \\
\text { Size }\end{array}$ & $\begin{array}{c}\text { Whole } \\
\text { head } \\
\text { imaging }\end{array}$ \\
\hline $\begin{array}{l}\text { Bozkurt et al., } \\
2005[30]\end{array}$ & $\begin{array}{l}\text { NI DAQcard 1200, } \\
\text { Control circuit, PC } \\
\text { / No }\end{array}$ & $\begin{array}{c}1 / 2 / \\
2 \mathrm{~cm} / \\
\mathrm{LED}, \mathrm{SiPD}\end{array}$ & No & No & Yes & 10 & 12 & $\begin{array}{c}\mathrm{No} / \\
\text { Tabletop } \\
\text { system }\end{array}$ & No \\
\hline $\begin{array}{l}\text { Yurtsever et al., } \\
2006[36]\end{array}$ & $\begin{array}{l}\text { NI DAQcard 6024E, } \\
\text { Control circuit, Pocket PC } \\
\text { / No }\end{array}$ & $\begin{array}{c}4 / 10 / \\
2.5 \mathrm{~cm} / \\
\text { LED, SiPD }\end{array}$ & No & Yes & Yes & 3.3 & 12 & $\begin{array}{c}\text { Yes/ } \\
\text { Lightweight }\end{array}$ & No \\
\hline $\begin{array}{l}\text { Atsumori et al., } \\
2007 \text { [53] }\end{array}$ & $\begin{array}{c}\text { FPGA, Processing } \\
\text { unit, Note-PC } \\
/ \text { - }\end{array}$ & $\begin{array}{c}8 / 8 / \\
3 \mathrm{~cm} / \\
\text { VCSEL, SiPD }\end{array}$ & No & Yes & Yes & 5 & - & $\begin{array}{c}\mathrm{No} / \\
1 \text { kilogram } \\
\text { carriable }\end{array}$ & No \\
\hline $\begin{array}{l}\text { Piper et al., } \\
2014 \text { [17] }\end{array}$ & $\begin{array}{c}\text { NI DAQcard 6216, } \\
\text { Control PCB , Note-PC } \\
\text { / No }\end{array}$ & $\begin{array}{c}8 / 8 / \\
2.5 \pm 0.3 \mathrm{~cm} / \\
\text { LED, SiPD }\end{array}$ & Yes & No & - & 6.25 & 16 & $\begin{array}{c}\mathrm{No} / \\
\text { Bagpack } \\
\text { carriable }\end{array}$ & Yes \\
\hline $\begin{array}{c}\text { McKendrick et al., } \\
2015 \text { [35] }\end{array}$ & $\begin{array}{c}8051 \mu \mathrm{C}, \mathrm{TI} \text { CC } 2430 \\
\text {, Control PCB, PC [54] } \\
\text { / No }\end{array}$ & $\begin{array}{c}1 / 2 / \\
2.5 \mathrm{~cm} / \\
\text { LED, SiPD }\end{array}$ & No & Yes & - & 4 & 12 & $\begin{array}{c}\text { Yes/ } \\
\text { Lightweight }\end{array}$ & No \\
\hline $\begin{array}{l}\text { Agro et al., } \\
2016 \text { [50] }\end{array}$ & $\begin{array}{c}\text { ARM STM32F4 } \mu \mathrm{C} \\
\text {, Flexible PCB/ PC } \\
/ \text { No }\end{array}$ & $\begin{array}{c}4 / 16 / \\
2.6 \mathrm{~cm} / \\
\text { LED, SiPM }\end{array}$ & No & No & No & - & 12 & $\begin{array}{c}\mathrm{No} / \\
-\end{array}$ & No \\
\hline $\begin{array}{c}\text { Saikia et al., } \\
\text { 2018, [proposed } \\
\text { system] }\end{array}$ & $\begin{array}{l}\text { IoT, Intel Edison SoC } \\
\text {, Control circuit } \\
\text { / Yes }\end{array}$ & $\begin{array}{c}8 / 16 / \\
4 \pm 0.5 \mathrm{~cm} / \\
\mathrm{LED}, \mathrm{SiPD}\end{array}$ & Yes & Yes & Yes & 11 & 24 & $\begin{array}{c}\text { Yes/ } \\
250 \text { gm } \\
\text { Lightweight }\end{array}$ & Yes \\
\hline
\end{tabular}

region of the brain. Figure 9 presents the topographic image of hemodynamic brain activities on the prefrontal cortex of a participant during the experiment. The $\mathrm{HbO}_{2}$ and $\mathrm{Hb}$ map at different important time frames are shown in order to visualize brain activity in response to the breathing exercise.

\section{DISCUSSION}

We focused on the design and development of a new generation fNIRS hardware and software interface based on modern embedded system architecture for the wireless wearable brain monitoring. We have also emphasized highly sensitive comfortable optode design that can be mounted in a generalpurpose electrode cap to place on the head. We have exploited the $3 \mathrm{D}$ printing technology to design the optode holders and a secure hardware enclosure. The system can be worn around the waist to perform experiments to image hemodynamic activities of a brain in a naturalistic environment.

We configure, control, and acquire data remotely in realtime using a host computer. The system was experimentally evaluated with two sets of preliminary experiments. The hemodynamic response of the muscle tissue in the arterial occlusion experiment, shown in the section IV-A, proves that the WearLight fNIRS system works properly. The prefrontal 
cortex experimental results in section IV-B shows that the system can image hemodynamic activities of the brain. The expected heart rate variation in the breathing exercise also can be observed in the raw experimental data.

There are many challenges in designing a completely configurable battery-operated multi-channel wearable wireless fNIRS system that can scan the entire brain cortical surface continuously at a high frame rate. The research on portable fNIRS development is growing and some of the innovative fNIRS systems, developed by researchers are mentioned in the section II-B. Table II presents the comparison between our proposed system with others. These systems have their own unique advantages and disadvantages. Some of them are not portable enough to carry with the user or they are constrained to operate in a special experimental condition. On the other hand, most of them are not suitable to integrate with EEG electrodes in a general purpose electrode cap to scan the hairy head. Some of fNIRS devices in Table II have fewer fNIRS channel, low frame rate, and limited dynamic range. Due to poor sensitivity of the fNIRS channel, they can not be operated with greater SD separations on the hairy head. Though some of the systems are wearable, it is difficult to classify them as a wearable device as they are wire connected to a PC or a heavy control system. Also, IoT concept based embedded system computing, wireless configurability and complete hardwareGUI software interface were not the focus of their studies for real-time data acquisition, processing and display.

In this work, we have proposed a new generation fNIRS system that has the potential to address some of the common challenges associated with hardware, software, configurability, comfort and EEG integration. However, some of the challenges pertaining to the multi-channel wearable fNIRS imaging still remain unaddressed. A single WearLight unit only supports up to 8 dual-wavelength light sources and 16 detectors, and using a single unit, whole brain imaging is not possible. Also, real-time intensive data processing in order to image a brain while participant performing sport was unattempted. However, WearLight allows experiments involving participants performing physical activities. This can advance the fNIRS signal processing domain to find methods for real-time processing of fNIRS data to image a brain in the real world conditions. The preliminary experimental studies evaluate the working of the system. However, we shall perform future studies for more comprehensive brain imaging backed by dedicated experimental protocols. We also desire to integrate EEG with highly sensitive tri-polar concentric ring electrode (TCRE) and our fNIRS system for the multi-modal brain imaging in future studies.

\section{ACKNOWLEDGMENT}

This material is based upon work supported by the National Science Foundation under Grant No. 1539068. The authors would also like to thank Gozde Cay and Dylan Kennedy for their assistance.

\section{REFERENCES}

[1] C. HOCK, K. VILLRINGER, F. MÜLLER-SPAHN, M. HOFMANN, S. SCHUH-HOFER, H. HEEKEREN, R. WENZEL, U. DIRNAGL, and A. VILLRINGER, "Near infrared spectroscopy in the diagnosis of alzheimer's diseasea," Annals of the New York Academy of Sciences, vol. 777, no. 1, pp. 22-29, 1996. [Online]. Available: http://dx.doi.org/10. 1111/j.1749-6632.1996.tb34397.x

[2] F. Irani, S. M. Platek, S. Bunce, A. C. Ruocco, and D. Chute, "Functional near infrared spectroscopy (fnirs): An emerging neuroimaging technology with important applications for the study of brain disorders," The Clinical Neuropsychologist, vol. 21, no. 1, pp. 9-37, 2007, pMID: 17366276. [Online]. Available: https://doi.org/10.1080/13854040600910018

[3] A.-C. Ehlis, S. Schneider, T. Dresler, and A. J. Fallgatter, "Application of functional near-infrared spectroscopy in psychiatry," NeuroImage, vol. 85, pp. $478-488,2014$, celebrating 20 Years of Functional Near Infrared Spectroscopy (fNIRS). [Online]. Available: http://www. sciencedirect.com/science/article/pii/S1053811913003200

[4] V. Quaresima and M. Ferrari, "Functional near-infrared spectroscopy (fnirs) for assessing cerebral cortex function during human behavior in natural/social situations: A concise review," Organizational Research Methods, p. 1094428116658959, 2018/01/21 2016. [Online]. Available: https://doi.org/10.1177/1094428116658959

[5] V. Kumar, V. Shivakumar, H. Chhabra, A. Bose, G. Venkatasubramanian, and B. N. Gangadhar, "Functional near infra-red spectroscopy (fnirs) in schizophrenia: A review," Asian Journal of Psychiatry, vol. 27, pp. 18 - 31, 2017. [Online]. Available: http://www.sciencedirect.com/science/ article/pii/S1876201816304348

[6] N. K. Logothetis, "What we can do and what we cannot do with fmri," Nature, vol. 453, no. 7197, pp. 869-878, 2008.

[7] M. A. Yücel, J. J. Selb, T. J. Huppert, M. A. Franceschini, and D. A. Boas, "Functional near infrared spectroscopy: Enabling routine functional brain imaging," Current Opinion in Biomedical Engineering, vol. 4, no. Supplement C, pp. 78 - 86, 2017. [Online]. Available: http://www.sciencedirect.com/science/article/pii/S2468451117300697

[8] G. Strangman, J. P. Culver, J. H. Thompson, and D. A. Boas, "A quantitative comparison of simultaneous bold fmri and nirs recordings during functional brain activation," NeuroImage, vol. 17, no. 2, pp. 719 - 731, 2002. [Online]. Available: http://www.sciencedirect.com/science/ article/pii/S1053811902912279

[9] J. A. Noah, Y. Ono, Y. Nomoto, S. Shimada, A. Tachibana, X. Zhang, S. Bronner, and J. Hirsch, "fmri validation of fnirs measurements during a naturalistic task," Journal of Visualized Experiments : JoVE, no. 100, p. 52116, 2015. [Online]. Available: http://www.ncbi.nlm.nih.gov/pmc/ articles/PMC4544944/

[10] F. F. Jöbsis, "Noninvasive, infrared monitoring of cerebral and myocardial oxygen sufficiency and circulatory parameters," Science, vol. 198 , no. 4323, pp. 1264-1267, 1977. [Online]. Available: http://www.jstor.org/ stable $/ 1745848$

[11] M. Firbank, E. Okada, and D. T. Delpy, "A theoretical study of the signal contribution of regions of the adult head to near-infrared spectroscopy studies of visual evoked responses," NeuroImage, vol. 8, no. 1, pp. 69 - 78, 1998. [Online]. Available: http://www.sciencedirect.com/science/ article/pii/S1053811998903482

[12] M. Ferrari and V. Quaresima, "A brief review on the history of human functional near-infrared spectroscopy (fnirs) development and fields of application," NeuroImage, vol. 63, no. 2, pp. 921 - 935, 2012. [Online]. Available: http://www.sciencedirect.com/science/article/ pii/S1053811912003308

[13] N. Naseer and K.-S. Hong, "fnirs-based brain-computer interfaces: a review," Frontiers in Human Neuroscience, vol. 9, p. 3, 2015. [Online]. Available: http://journal.frontiersin.org/article/10.3389/fnhum.2015.00003

[14] A. T. Eggebrecht, S. L. Ferradal, A. Robichaux-Viehoever, M. S. Hassanpour, H. Dehghani, A. Z. Snyder, T. Hershey, and J. P. Culver, "Mapping distributed brain function and networks with diffuse optical tomography," Nature Photonics, vol. 8, pp. 448 EP -, 05 2014. [Online]. Available: http://dx.doi.org/10.1038/nphoton.2014.107

[15] M. A. Franceschini, V. Toronov, M. E. Filiaci, E. Gratton, and S. Fantini, "On-line optical imaging of the human brain with 160-ms temporal resolution," Opt. Express, vol. 6, no. 3, pp. 49-57, Jan 2000. [Online]. Available: http://www.opticsexpress.org/abstract.cfm?URI=oe-6-3-49

[16] M. M. Ravicz, K. L. Perdue, A. Westerlund, R. E. Vanderwert, and C. A. Nelson, "Infants' neural responses to facial emotion in the prefrontal cortex are correlated with temperament: a functional near-infrared spectroscopy study," Frontiers in Psychology, vol. 6, p. 922, 2015. [Online]. Available: https://www.frontiersin.org/article/10.3389/fpsyg.2015.00922

[17] S. K. Piper, A. Krueger, S. P. Koch, J. Mehnert, C. Habermehl, J. Steinbrink, H. Obrig, and C. H. Schmitz, "A wearable multi-channel fnirs system for brain imaging in freely moving subjects," NeuroImage, vol. 85, pp. 64 - 71, 2014, celebrating 20 Years of Functional 
Near Infrared Spectroscopy (fNIRS). [Online]. Available: http://www. sciencedirect.com/science/article/pii/S1053811913007003

[18] S. Ahn and S. C. Jun, "Multi-modal integration of eeg-fnirs for braincomputer interfaces - current limitations and future directions," Frontiers in Human Neuroscience, vol. 11, p. 503, 2017. [Online]. Available: https: //www.frontiersin.org/article/10.3389/fnhum.2017.00503

[19] F. Wallois, M. Mahmoudzadeh, A. Patil, and R. Grebe, "Usefulness of simultaneous eeg-nirs recording in language studies," Brain and Language, vol. 121, no. 2, pp. 110 - 123, 2012, functional Near-Infra Red Spectroscopy (fNIRS): A Promising Functional Imaging Technique for the Study of Brain and Language. [Online]. Available: http://www. sciencedirect.com/science/article/pii/S0093934X11000599

[20] D. K. Nguyen, J. Tremblay, P. Pouliot, P. Vannasing, O. Florea, L. Carmant, F. Lepore, M. Sawan, F. Lesage, and M. Lassonde, "Non-invasive continuous eeg-fnirs recording of temporal lobe seizures," Epilepsy Research, vol. 99, no. 1, pp. 112 - 126, 2012. [Online]. Available: http://www.sciencedirect.com/science/article/pii/S0920121111003627

[21] B. Chance, Z. Zhuang, C. UnAh, C. Alter, and L. Lipton, "Cognitionactivated low-frequency modulation of light absorption in human brain." Proceedings of the National Academy of Sciences of the United States of America, vol. 90, no. 8, pp. 3770-3774, 04 1993. [Online]. Available: http://www.ncbi.nlm.nih.gov/pmc/articles/PMC46383/

[22] A. Yodh and B. Chance, "Spectroscopy and imaging with diffusing light," Physics Today, vol. 48, no. 3, pp. 34-41, 1995.

[23] M. Cope, "The development of a near infrared spectroscopy system and its application for non invasive monitoring of cerebral blood and tissue oxygenation in the newborn infants," Ph.D. dissertation, University of London, 1991.

[24] "Optical absorption of hemoglobin.” [Online]. Available: http://omlc.ogi. edu/spectra/

[25] H. Dehghani, B. R. White, B. W. Zeff, A. Tizzard, and J. P. Culver, "Depth sensitivity and image reconstruction analysis of dense imaging arrays for mapping brain function with diffuse optical tomography," Appl. Opt., vol. 48, no. 10, pp. D137-D143, Apr 2009. [Online]. Available: http://ao.osa.org/abstract.cfm?URI=ao-48-10-D137

[26] M. J. Saikia and R. Kanhirodan, "High performance single and multigpu acceleration for diffuse optical tomography," in 2014 International Conference on Contemporary Computing and Informatics (IC3I), 2014, pp. 1320-1323.

[27] _ , "Region-of-interest diffuse optical tomography system," Review of Scientific Instruments, vol. 87, no. 1, p. 013701, 2016. [Online]. Available: https://doi.org/10.1063/1.4939054

[28] M. J. Saikia, R. Manjappa, K. Mankodiya, and R. Kanhirodan, "Depth sensitivity improvement of region-of-interest diffuse optical tomography from superficial signal regression," in Imaging and Applied Optics 2018 (3D, AO, AIO, COSI, DH, IS, LACSEA, LS\&C, MATH, pcAOP). Optical Society of America, 2018, p. CM3E.5. [Online]. Available: http://www. osapublishing.org/abstract.cfm?URI=COSI-2018-CM3E.5

[29] S. M. Liao, S. L. Ferradal, B. R. White, N. Gregg, T. E. Inder, and J. P. Culver, "High-density diffuse optical tomography of term infant visual cortex in the nursery," Journal of Biomedical Optics, vol. 17, no. 8, p. 081414, 08 2012. [Online]. Available: http://www.ncbi.nlm.nih.gov/pmc/ articles/PMC3391961/

[30] A. Bozkurt, A. Rosen, H. Rosen, and B. Onaral, "A portable near infrared spectroscopy system for bedside monitoring of newborn brain," BioMedical Engineering OnLine, vol. 4, no. 1, p. 29, Apr 2005. [Online]. Available: https://doi.org/10.1186/1475-925X-4-29

[31] B. R. White and J. P. Culver, "Phase-encoded retinotopy as an evaluation of diffuse optical neuroimaging," NeuroImage, vol. 49, no. 1, pp. 568 - 577, 2010. [Online]. Available: http://www.sciencedirect.com/science/ article/pii/S1053811909007939

[32] M. J. Saikia, R. Manjappa, and R. Kanhirodan, "A cost-effective led and photodetector based fast direct $3 \mathrm{~d}$ diffuse optical imaging system," in Diffuse Optical Spectroscopy and Imaging VI. Optical Society of America, 2017, p. 104120Y. [Online]. Available: http://www.osapublishing.org/ abstract.cfm?URI=ECBO-2017-104120Y

[33] M. J. Saikia, R. Kanhirodan, and R. M. Vasu, "High-speed gpu-based fully three-dimensional diffuse optical tomographic system," Journal of Biomedical Imaging, vol. 2014, pp. 3:3-3:3, Jan. 2014. [Online]. Available: http://dx.doi.org/10.1155/2014/376456

[34] S. M. Coyle, T. E. Ward, and C. M. Markham, "Brain-computer interface using a simplified functional near-infrared spectroscopy system," Journal of Neural Engineering, vol. 4, no. 3, p. 219, 2007. [Online]. Available: http://stacks.iop.org/1741-2552/4/i=3/a=007

[35] R. McKendrick, R. Parasuraman, and H. Ayaz, "Wearable functional near infrared spectroscopy (fnirs) and transcranial direct current stimulation (tdcs): expanding vistas for neurocognitive augmentation," Fron- tiers in Systems Neuroscience, vol. 9, p. 27, 2015. [Online]. Available: http://journal.frontiersin.org/article/10.3389/fnsys.2015.00027

[36] G. Yurtsever, F. Kepics, and A. Bozkurt, "Wireless continuous wave near infrared imager," in 2003 IEEE 29th Annual Proceedings of Bioengineering Conference, March 2003, pp. 53-54.

[37] M. Abtahi, G. Cay, M. J. Saikia, and K. Mankodiya, "Designing and testing a wearable, wireless fnirs patch," in 2016 38th Annual International Conference of the IEEE Engineering in Medicine and Biology Society (EMBC), Aug 2016, pp. 6298-6301.

[38] A. Villringer and B. Chance, "Non-invasive optical spectroscopy and imaging of human brain function," Trends in Neurosciences, vol. 20, no. 10, pp. 435 - 442, 1997. [Online]. Available: http://www. sciencedirect.com/science/article/pii/S0166223697011326

[39] T. J. Huppert, S. G. Diamond, M. A. Franceschini, and D. A. Boas, "Homer: a review of time-series analysis methods for near-infrared spectroscopy of the brain," Appl. Opt., vol. 48, no. 10, pp. D280D298, Apr 2009. [Online]. Available: http://ao.osa.org/abstract.cfm?URI= ao-48-10-D280

[40] L. Kocsis, P. Herman, and A. Eke, "The modified beer-lambert law revisited," Physics in Medicine \& Biology, vol. 51, no. 5, p. N91, 2006. [Online]. Available: http://stacks.iop.org/0031-9155/51/i=5/a=N02

[41] D. T. Delpy, M. Cope, P. van der Zee, S. Arridge, S. Wray, and J. Wyatt, "Estimation of optical pathlength through tissue from direct time of flight measurement," Physics in Medicine \& Biology, vol. 33, no. 12, p. 1433 , 1988. [Online]. Available: http://stacks.iop.org/0031-9155/33/i=12/a=008

[42] S. Brigadoi, L. Ceccherini, S. Cutini, F. Scarpa, P. Scatturin, J. Selb, L. Gagnon, D. A. Boas, and R. J. Cooper, "Motion artifacts in functional near-infrared spectroscopy: A comparison of motion correction techniques applied to real cognitive data," Neurolmage, vol. 85, pp. 181 - 191, 2014, celebrating 20 Years of Functional Near Infrared Spectroscopy (fNIRS). [Online]. Available: http://www.sciencedirect.com/ science/article/pii/S1053811913004291

[43] M. Sood, P. Besson, M. Muthalib, U. Jindal, S. Perrey, A. Dutta, and M. Hayashibe, "Nirs-eeg joint imaging during transcranial direct current stimulation: Online parameter estimation with an autoregressive model," Journal of Neuroscience Methods, vol. 274, pp. 71 - 80, 2016. [Online]. Available: http://www.sciencedirect.com/science/article/ pii/S0165027016302163

[44] G. Gallegos-Ayala, A. Furdea, K. Takano, C. A. Ruf, H. Flor, and N. Birbaumer, "Brain communication in a completely locked-in patient using bedside near-infrared spectroscopy," Neurology, vol. 82, no. 21, pp. 1930-1932, 2014. [Online]. Available: http://n.neurology.org/content/82/ $21 / 1930$

[45] U. Chaudhary, N. Birbaumer, and A. Ramos-Murguialday, "Braincomputer interfaces for communication and rehabilitation," Nature Reviews Neurology, vol. 12, pp. 513 EP -, 08 2016. [Online]. Available: http://dx.doi.org/10.1038/nrneurol.2016.113

[46] G. Kaimal, H. Ayaz, J. Herres, R. Dieterich-Hartwell, B. Makwana, D. H. Kaiser, and J. A. Nasser, "Functional near-infrared spectroscopy assessment of reward perception based on visual self-expression: Coloring, doodling, and free drawing," The Arts in Psychotherapy, vol. 55, pp. 85 - 92, 2017. [Online]. Available: http://www.sciencedirect.com/science/ article/pii/S019745561630171X

[47] M. Izzetoglu, K. Izzetoglu, S. Bunce, H. Ayaz, A. Devaraj, B. Onaral, and K. Pourrezaei, "Functional near-infrared neuroimaging," IEEE Transactions on Neural Systems and Rehabilitation Engineering, vol. 13, no. 2, pp. 153-159, 2005.

[48] E. Kamrani, F. Lesage, and M. Sawan, "Fully on-chip integrated photodetector front-end dedicated to real-time portable optical brain imaging," Optics and Photonics Journal, vol. Vol.02No.04, p. 13 , 2012. [Online]. Available: //www.scirp.org/journal/PaperInformation. aspx?PaperID=25968\%]25968

[49] D. Chitnis, D. Airantzis, D. Highton, R. Williams, P. Phan, V. Giagka, S. Powell, R. J. Cooper, I. Tachtsidis, M. Smith, C. E. Elwell, J. C. Hebden, and N. Everdell, "Towards a wearable near infrared spectroscopic probe for monitoring concentrations of multiple chromophores in biological tissue in vivo," Review of Scientific Instruments, vol. 87, no. 6 , p. 065112, 2016. [Online]. Available: https://doi.org/10.1063/1.4954722

[50] D. Agrò, R. Canicattì, M. Pinto, G. Morsellino, A. Tomasino, G. Adamo, L. Curcio, A. Parisi, S. Stivala, N. Galioto et al., "Design and implementation of a portable fnirs embedded system," in Applications in Electronics Pervading Industry, Environment and Society. Springer, 2016, pp. 43-50.

[51] A. von Lühmann, H. Wabnitz, T. Sander, and K. R. Müller, "M3ba: A mobile, modular, multimodal biosignal acquisition architecture for miniaturized eeg-nirs-based hybrid bci and monitoring," IEEE Transactions on Biomedical Engineering, vol. 64, no. 6, pp. 1199-1210, 2017. 
[52] M. J. Saikia and R. Kanhirodan, "Development of dot system for roi scanning," in 12th International Conference on Fiber Optics and Photonics. Optical Society of America, 2014, p. T3A.4. [Online]. Available: http://www.osapublishing.org/abstract.cfm?URI=Photonics-2014-T3A.4

[53] H. Atsumori, M. Kiguchi, A. Obata, H. Sato, T. Katura, K. Utsugi, T. Funane, and A. Maki, "Development of a multi-channel, portable optical topography system," in 2007 29th Annual International Conference of the IEEE Engineering in Medicine and Biology Society, 2007, pp. 3362-3364.

[54] H. Ayaz, B. Onaral, K. Izzetoglu, P. A. Shewokis, R. McKendrick, and R. Parasuraman, "Continuous monitoring of brain dynamics with functional near infrared spectroscopy as a tool for neuroergonomic research: empirical examples and a technological development," Frontiers in Human Neuroscience, vol. 7, p. 871, 2013. [Online]. Available: http://www.ncbi.nlm.nih.gov/pmc/articles/PMC3866520/

[55] A. Bozkurt and B. Onaral, "Safety assessment of near infrared ligh emitting diodes for diffuse optical measurements," BioMedical Engineering OnLine, vol. 3, pp. 9 - 9, 2004.

[56] R. Cooper, J. Selb, L. Gagnon, D. Phillip, H. Schytz, H. Iversen, M. Ashina, and D. Boas, "A systematic comparison of motion artifact correction techniques for functional near-infrared spectroscopy," Frontiers in Neuroscience, vol. 6, p. 147, 2012. [Online]. Available: https://www.frontiersin.org/article/10.3389/fnins.2012.00147

[57] M. A. F. D. A. B. Yiheng Zhang, Dana H. Brooks, "Eigenvectorbased spatial filtering for reduction of physiological interference in diffuse optical imaging," Journal of Biomedical Optics, vol. 10, pp. $10-10-$ 11, 2005. [Online]. Available: https://doi.org/10.1117/1.1852552

[58] H. Santosa, M. Jiyoun Hong, S.-P. Kim, and K.-S. Hong, "Noise reduction in functional near-infrared spectroscopy signals by independent component analysis," Review of Scientific Instruments, vol. 84, no. 7, p. 073106, 2013. [Online]. Available: https://doi.org/10.1063/1.4812785

[59] M. Izzetoglu, P. Chitrapu, S. Bunce, and B. Onaral, "Motion artifact cancellation in nir spectroscopy using discrete kalman filtering," BioMedical Engineering OnLine, vol. 9, no. 1, p. 16, 2010. [Online]. Available: https://doi.org/10.1186/1475-925X-9-16

[60] X. Cui, S. Bray, and A. L. Reiss, "Functional near infrared spectroscopy (nirs) signal improvement based on negative correlation between oxygenated and deoxygenated hemoglobin dynamics," NeuroImage, vol. 49, no. 4, pp. 3039 - 3046, 2010. [Online]. Available: http: //www.sciencedirect.com/science/article/pii/S105381190901235X

[61] B. Molavi and G. A. Dumont, "Wavelet-based motion artifact removal for functional near-infrared spectroscopy," Physiological Measurement, vol. 33, no. 2, p. 259, 2012. [Online]. Available: http://stacks.iop.org/ $0967-3334 / 33 / \mathrm{i}=2 / \mathrm{a}=259$

[62] F. Scholkmann, S. Spichtig, T. Muehlemann, and M. Wolf, "How to detect and reduce movement artifacts in near-infrared imaging using moving standard deviation and spline interpolation," Physiological Measurement, vol. 31, no. 5, p. 649, 2010. [Online]. Available: http: //stacks.iop.org/0967-3334/31/i=5/a=004

[63] Y. Shang, Y. Zhao, R. Cheng, L. Dong, D. Irwin, and G. Yu, "Portable optical tissue flow oximeter based on diffuse correlation spectroscopy," Opt. Lett., vol. 34, no. 22, pp. 3556-3558, Nov 2009. [Online]. Available: http://ol.osa.org/abstract.cfm?URI=ol-34-22-3556

[64] K. Singh, H. Bhargav, and T. Srinivasan, "Effect of uninostril yoga breathing on brain hemodynamics: A functional near-infrared spectroscopy study," International Journal of Yoga, vol. 9, no. 1, pp. 1219, Jan-Jun 2016. [Online]. Available: http://www.ncbi.nlm.nih.gov/pmc/ articles/PMC4728953/

[65] S. Deepeshwar, S. A. Vinchurkar, N. K. Visweswaraiah, and H. R. Nagendra, "Hemodynamic responses on prefrontal cortex related to meditation and attentional task," Frontiers in Systems Neuroscience, vol. 8 , p. 252, 2015. [Online]. Available: https://www.frontiersin.org/article/10. 3389/fnsys.2014.00252

[66] R. B. Ankad, A. Herur, S. Patil, G. Shashikala, and S. Chinagudi, "Effect of short-term pranayama and meditation on cardiovascular functions in healthy individuals," Heart Views : The Official Journal of the Gulf Heart Association, vol. 12, no. 2, pp. 58-62, Apr-Jun 2011. [Online]. Available: http://www.ncbi.nlm.nih.gov/pmc/articles/PMC3221193/

[67] "Yogasynergy," $2009 . \quad$ [Online]. Available: https://yogasynergy.com/2010/08/10/ how-to-slow-the-heart-from-88-beats-to-32-beat-per-minute-in-45-seconds/

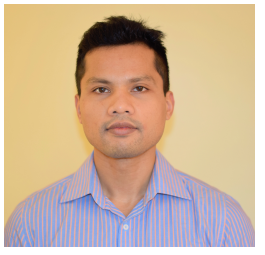

Manob Jyoti Saikia $\left(S^{\prime} 15\right)$ received his B.E. degree in Electronics and Communication Engineering from the Visvesvaraya Technological University, India, in 2009 and an M.Tech. degree in Bioelectronics from the Tezpur University, India, in 2013. Currently, he is working toward the Ph.D. degree in the Electrical, Computer and Biomedical Engineering Department, University of Rhode Island, USA. From 2012 to 2016, he was a Research Fellow with the Indian Institute of Science, India. His research interests include medical diagnostic systems, wearable health monitoring systems, medical devices, biomedical imaging, and electronic design.

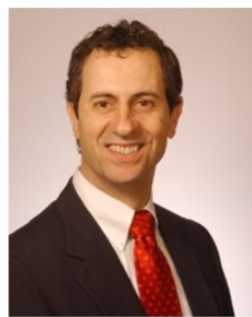

Walter G. Besio $\left(\mathrm{S}^{\prime} 92-\mathrm{M}^{\prime} 02-\mathrm{SM}^{\prime} 06\right)$ received the B.S.E.E. degree from University of Central Florida, Orlando, in 1993, and the M.S. and Ph.D. degrees in biomedical engineering from University of Miami, Coral Gables, FL, in 1997 and 2002, respectively. From 2002 to 2007, he was an Assistant Professor in the Biomedical Engineering Department, Louisiana Tech University, Ruston. Since 2008, he has been in the Electrical, Computer, and Biomedical Engineering Department at the University of Rhode Island, Kingston, RI. Prior to joining academia, he worked in the medical device and electronics industries. His major research interests include electrode design, Laplacian EEG, neuro-modulation, epilepsy, and brain computer interfacing. Professor Besio's lab performs theoretical and applied research to develop novel medical devices and therapies to enhance the lives of persons with disease and disability.

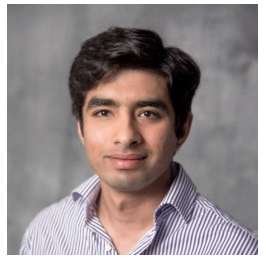

Kunal Mankodiya (S'08-M'14) received his B.E. degree in Biomedical Engineering from the Saurashtra University, India, in 2003, M.S. degree in Biomedical Engineering and the Ph.D. degree in Computer Science from University of Luebeck, Germany in 2007 and 2010, respectively. He is currently an assistant professor of Biomedical Engineering and the Director of Wearable Biosensing Lab in the Dept. of Electrical, Computer, and Biomedical Engineering, University of Rhode Island, RI, USA. From 2011 to 2014, he was a postdoctoral researcher at Intel Science and Technology Center (ISTC) affiliated with Carnegie Mellon University (CMU), Pittsburgh, PA, USA. He is a recipient of TechConnect Defense Innovation Award (2018), NSF CAREER Award (2017), Innovatorof-the-year Future Textiles Award - Germany (2017), 40 under 40 Providence Business News Award (2017), NSF CRII Award (2016) and the 2010 SYSTEX Award - Belgium (2010) 